\title{
BMJ Open A prospective cohort study of hospital separations among people who inject drugs in Australia: 2008-2013
}

\author{
Dhanya Nambiar, ${ }^{1}$ Mark Stoové, ${ }^{1}$ Matthew Hickman, ${ }^{2}$ Paul Dietze ${ }^{1}$
}

To cite: Nambiar D, Stoové $M$, Hickman $\mathrm{M}$, et al. A prospective cohort study of hospital separations among people who inject drugs in Australia: 2008-2013. BMJ Open 2017;7:e014854. doi:10.1136/ bmjopen-2016-014854

- Prepublication history for this paper is available online. To view these files please visit the journal online (http://dx.doi. org/10.1136/bmjopen-2016014854).

Received 24 0ctober 2016 Revised 9 June 2017 Accepted 16 June 2017

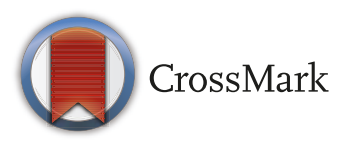

${ }^{1}$ Centre for Population Health, Burnet Institute, Melbourne, Victoria, Australia

${ }^{2}$ School of Social and Community Medicine, University of Bristol, Bristol, UK

Correspondence to Dhanya Nambiar; dhanya@burnet.edu.au

\section{ABSTRACT}

Objectives Injecting drug use is a persistent behaviour that increases the risk of morbidities and mortality. We assessed the burden of hospital separations among people who inject drugs (PWID), the excess compared to the general population and characteristics of separations associated with frequent use.

Design Prospective cohort study.

Setting All public and private hospitals in Victoria. Participants 757 community-based PWID with hospital separations between January 2008 and June 2013 identified through record linkage, who contributed over 3729 person-years.

Primary and secondary outcome measures Counts, proportions and rates of hospital separations, descriptive administrative data including all diagnoses, comparison of separation rates to the general population, trend in separations and factors associated with frequent separations.

Results There were 2106 separations in the cohort. The most common principal diagnoses were related to mental and behavioural disorders (31\%), but social circumstances influencing health was the most common group of diagnoses $(61 \%)$ when all contributing diagnoses for each patient were considered. Separation rates were up to three times higher than in the age-matched population, and there was a $12 \%$ increase in separations every 6 months. Over a quarter $(29 \%)$ of the cohort had frequent separations (defined as two or more separations in a calendar year), which were associated with mental healthrelated diagnoses, being discharged to locations other than a patient's residence, having a medical as opposed to surgical intervention, seasonal patterns, relationship status and gender.

Conclusions Mental health conditions and other characteristics associated with separations and frequent separations in particular, emphasise the importance of providing referrals to harm reduction, social services and mental health services at discharge in order to reduce excess hospital separations among PWID.

\section{BACKGROUND}

People who inject drugs (PWID) are known to experience a wide range of morbidities ${ }^{12}$ that require health service intervention provided in hospital settings. ${ }^{3} 4$ Previous research has shown that PWID frequently attend emergency departments (EDs), ${ }^{56}$ but it is not clear

\section{Strengths and limitations of this study}

The cohort was recruited through community settings rather than drug treatment or needlesyringe exchange services, which increases the generalisability of the results to the broader people who inject drugs (PWID) community.

- Record linkage provides administrative data on all hospitals in Victoria, whereas most studies have been based on a single hospital.

- The observation period was $5 \frac{1}{2}$ years, which is longer than other studies describing hospital presentations among PWID.

- Deterministic record linkage has high specificity but low sensitivity, hence separation rates reported are likely to be conservative.

- The observation period overlaps with the roll-out of the National Emergency Access Target, which may have increased admissions through emergency departments, although it is expected that this would also apply to the wider population.

whether they are also frequently admitted to hospitals. ED presentations are focused at least initially on acute health needs, and may not provide a comprehensive description of the health conditions that may lead to more extensive use of hospital services, as they do not always result in admission. Hospital separations data, which for the purposes of this paper we have equated with admissions, ${ }^{7}$ generally provide more detail on clinical conditions, interventions and referrals. For example, data on ED presentations in the State of Victoria, Australia, include only one principal diagnosis and up to two additional diagnoses per presentation, ${ }^{8}$ while hospital separations can have up to 39 additional diagnoses. $^{9}$

The limited research available suggests that hospital separations occur more frequently among people who use drugs than the general population. ${ }^{10}{ }^{11}$ Hospital administrative records can be used to generate information on the frequency of presentation, clinical diagnoses and treatment and discharge plans 
in order to help understand the contributing factors. Common diagnoses among PWID reported in previous work on admissions include skin and soft tissue infections, mental and behavioural disorders, injury and poisoning, and drug-related disorders. ${ }^{42}{ }^{13}$ Social circumstances that affect health, such as homelessness, are also common among PWID ${ }^{14}$ and may contribute to increased use of hospital services due to multiple comorbidities and poor perceived access to medical care. ${ }^{15}$ It may be that a small proportion of PWID, who experience specific health and social conditions contributes to a large proportion of separations. For example, in a cross-sectional study of methamphetamine users in Sydney, two-thirds of whom were PWID, $16 \%$ reported a hospital separation in the previous year, but only $2 \%$ had two or more separations. ${ }^{16}$ Identifying characteristics of frequent users could assist the development of targeted services.

A few previous studies have used hospital administrative records for this purpose, but probably underascertained the number of separations among PWID. Palepu et $a l^{17}$ used records from only one hospital, so missed admissions among their PWID cohort at other hospitals. Marks $e t a l^{12}$ employed a similar single-centre design and relied on admission protocol to assess PWID status, risking underascertainment as physicians often care for PWID without specialist support and may not always identify substance use. ${ }^{4}$ Further, PWID may have multiple health and social conditions that contribute to separations and will not be captured if only principal diagnoses are considered, as was the case in both Palepu et $a l^{17}$ and Marks et al. ${ }^{12}$ The low prevalence of HIV among PWID in Australia compared with other countries where this kind of work has been undertaken, such as Canada ${ }^{17}$ may also affect the characteristics and frequency of hospital separations.

We are aware of no studies in Australia that have described longitudinal hospital separations among PWID, and none that include principal and contributing diagnoses and information on admission and discharge that could identify risk factors for frequent separations among PWID. This study describes the characteristics of hospital separations in a cohort of PWID in Melbourne between January 2008 and June 2013, as determined through record linkage with a statewide records system. We assessed trends in hospital separations among PWID and compared separation rates to those for the age-matched general population, and identified clinical diagnoses and other risk factors associated with frequent hospital separations in PWID.

\section{METHODS}

\section{Study population}

The Melbourne Injecting Drug User Cohort Study (MIX) recruited participants between 2008 and 2010 through a combination of respondent-driven sampling, snowball sampling and peer outreach. Participants resided in urban Melbourne, were aged 18 or over, regularly (at least monthly) injected either heroin or methamphetamine in the 6 months prior to baseline, and had a valid Medicare number (needed to access the Australian universal healthcare system). MIX was designed to explore, among other outcomes, health service use and health outcomes in a population of PWID, who are largely out of treatment, young and recent initiates into injecting drug use. The study was approved by the Victorian Department of Health (DoH) and Monash University Human Research Ethics Committees. Further details on the recruitment method and details of the cohort at baseline are available elsewhere. $^{18}$

\section{Data sources for hospital separations}

Administrative and clinical data related to presentations at Victorian public and private hospitals are collected by the DoH and stored as the Victorian Admitted Episodes Dataset (VAED). To identify hospital separations in the cohort, the DoH data conducted linkage to VAED records using deterministic linkage, with exact matches on identifying information provided by participants. Cohort records were linked to hospital separations between January 2008 and June 2013, and the final linkage was based on a $100 \%$ match across Medicare number, first three letters of the first name, date of birth and sex. Complete diagnoses at hospital separation were coded using the International Classification of Diseases, 10th revision, Australian Modification (ICD-10-AM. ${ }^{19}$ Data quality were assessed internally and the false-positive rate was estimated to be less than $5 \%$.

Age-specific hospital separation rates per 1000 personyears (PY) for the Greater Melbourne Capital City Statistical Division ${ }^{20}$ were calculated using supplementary population VAED data provided by the $\mathrm{DoH}$ and publicly available population size estimates from the Australian Bureau of Statistics (ABS) Population Estimates collection for the years 2008 to 2012.

\section{Dependent variables}

Hospital separation rates were calculated as the total number of separations divided by PY contributed by the cohort as a whole, and stratified by age groups. This allowed PWID separation rates to be compared with those for the age-matched population of the Greater Melbourne statistical area.

The ICD-10-AM clinical coding system includes chapter headings that correspond to major body systems, and each chapter contains a group of codes that narrows down the diagnosis. Diagnoses of interest were based on existing literature and grouped into clinical categories (similar to chapter headings) relevant to a young, community-based cohort of PWID (table 1). The specific clinical categories analysed were:

The majority of literature on hospital separations has focused on a main cause of the separation, typically considered to be the principal diagnosis as recorded by the attending physician. However, to account for documented problems with relying solely on the principal diagnosis, when separations can include multiple 
Table 1 Clinical categories and relevant ICD-10-AM diagnostic codes of interest

\begin{tabular}{|c|c|}
\hline Clinical categories for admission & ICD-10-AM diagnostic codes \\
\hline $\begin{array}{l}\text { Drug related*: } \\
\text { Drug-related mental and behavioural disorders, accidental and intended } \\
\text { poisoning, etc }\end{array}$ & $\begin{array}{l}\mathrm{F} 11.2-11.6, \mathrm{~F} 11.9, \mathrm{~F} 12-16, \mathrm{~F} 19, \mathrm{~T} 30-60, \mathrm{X} 40-45 \\
\mathrm{X} 85, \mathrm{Y} 10-14\end{array}$ \\
\hline $\begin{array}{l}\text { Injuries: } \\
\text { External causes including assault and accidents }\end{array}$ & $\begin{array}{l}\text { X40-49, X70-99, Y01-09, Y20-29, T10, T70-79, } \\
\text { N96-97, N99, all S, W and V codes }\end{array}$ \\
\hline Bacterial and skin infections & All L codes, A20-49, B40-49 \\
\hline Mental health & F01-09, F20-99 \\
\hline $\begin{array}{l}\text { Social circumstances: } \\
\text { Health hazards from communicable diseases such as hepatitis C, } \\
\text { socioeconomic and psychosocial factors and family and personal history }\end{array}$ & Z20-29, Z40-99 \\
\hline
\end{tabular}

*Based on Australian Bureau of Statistics definitions.

ICD-10-AM, International Classification of Diseases, 10th revision, Australian Modification.

diagnoses, ${ }^{3} 2122$ we included all diagnostic codes in the categories of interest in order to account for all contributing causes of the separation.

As there is no consistent or clinical definition of frequent hospital separations, we defined a priori frequent hospital separations as two or more separations within a calendar year. ${ }^{17}$ All separations for an individual in a calendar year were grouped into annual separation sets. Annual separation sets were defined as all separations for an individual in a calendar year, and included separations from 2008 to 2012. The outcome variable, frequent hospital separations, was coded as binary for all separations that formed part of an annual separation set.

\section{Independent variables}

Independent variables considered in the analyses were variables routinely collected at hospital separations that have previously been associated with frequent use of health services ${ }^{23} 24$ and clinical categories of interest to a cohort of PWID. These were age, gender, relationship status: single (yes, no/unknown), season, admission type, admission source, duration of stay, type of intervention, discharge status and clinical categories of interest.

The cohort was relatively young, with a skewed age distribution, and the administrative data provided age as a categorical variable. As a result, age was categorised (15-24, 25-29, 30-49 years) as presented in other papers describing the cohort. ${ }^{25}$ Admission type described how the patient was admitted, and included planned admissions or transfers, admissions through the ED and admissions related to maternal health. Discharge status was classified as home residence or other; the latter involved transfers to mental health residential facilities, transition care bed programmes, changes in care within the hospital, transfers to other hospitals and care services, deaths and patients who left against medical advice. Other presentation characteristics included in analysis were duration of stay (same day, overnight, multiday) and type of intervention (medical, surgical). Given potential seasonal variations, autumn was selected as the reference category to be consistent with our previous work.

\section{Statistical methods}

All data were organised as person-event record data, with participants contributing time from January 2008 to June 2013. All data were reported as event-level data, with sample sizes representing the number of events corresponding to the specified time period for analyses. The administrative records provided had no missing data.

Descriptive statistics were generated on all primary diagnoses. We report proportions by clinical categories of interest for primary diagnoses and all diagnoses in each separation. Separations can include more than one clinical category of interest, as patients often have multiple health conditions reported at discharge, so all the diagnoses that include clinical categories of interest were captured in the analyses.

Poisson regression was used to determine trends in hospital separation rates over the study period as biannual incidence rates with 95\% CIs. Models were adjusted for age, gender, season, type of care, patient type, admission type, duration of stay, relationship status, type of intervention and admission source.

Overall hospital separation rates with 95\% Poisson CI were estimated for the cohort and stratified by age group. We compared these to the age-matched general population hospital separation rates of the Greater Melbourne statistical area and reported the excess in the cohort as age-standardised rate ratios.

For the remainder of the analyses, hospital separations from 2013 were excluded to ensure they were comparable with the annual rates in the general population and the study population.

We calculated the prevalence of frequent hospital separations in the cohort and identified correlates of frequent presentations using generalised estimating equation (GEE) regression models. GEE allows for clustered data analysis involving repeated measures for the 
same individual, and is based on a population-averaged model that accounts for correlations between subjects using sandwich/robust variance estimators. We specified a binomial family with a logit link given the binary outcome (frequent vs non-frequent separations). All available diagnostic codes in each separation were included in the clinical categories to ensure complete capture of categories of interest, and multiple categories could be included for each separation. Other covariates were age, gender, relationship status: single, season, admission type, admission source, duration of stay, type of intervention, discharge status and clinical categories of interest. Variables significantly associated with the outcome at a bivariate level $(\mathrm{p}<0.05)$ were included in the adjusted model, with age, gender and clinical categories of interest included a priori. To test if there would be a difference in outcomes, when only the principal diagnoses were considered, we recoded the clinical categories of interest based on principal diagnosis alone as a sensitivity analysis. All analyses were conducted using Stata V.13.1.

\section{RESULTS}

\section{Baseline cohort characteristics}

There were 757 MIX participants who were linked to the VAED. At baseline, the median age of the cohort was 28 years (IQR 25-30) and most participants were men $(63 \%)$. The cohort was largely unemployed $(86 \%)$, over half $(59 \%)$ had been previously incarcerated and 19\% were homeless. Participants had been injecting for a median of 10 years (IQR 6-13); the main drug of choice was heroin $(72 \%)$ followed by amphetamines (12\%). A large majority $(79 \%)$ had ever been on drug treatment and over a third (35\%) reported current opioid substitution therapy. Over half (58\%) had been to a general practitioner (GP) in the month prior to their baseline interview. Further details are available elsewhere ${ }^{18}$ Over the study period, $64 \%$ of the cohort presented to public EDs at least once. Other than the relatively young age of the cohort, baseline characteristics are similar to other Australian cohort studies of PWID ${ }^{26} 27$.

\section{Characteristics of hospital admissions}

Among 757 PWID, there were 2106 separations over 4163.5 PY between January 2008 and June 2013. Over half $(55 \%)$ of the cohort had at least one separation in $5 \frac{1}{2}$ years. Among those admitted, the median number of separations was three (IQR 1-5) with a maximum of 93 separations.

The most common ICD-10-AM chapter heading for principal diagnosis was mental and behavioural disorders $(31 \%)$ (table 2); schizophrenia and borderline personality disorder were the most common principal diagnostic codes ( $6 \%$ and $4 \%$ respectively). The most common clinical specialty used was allied health (social work) (12\%).

When considering all diagnoses across clinical categories of interest, social circumstances contributed to the highest percentage of separations $(63 \%)$, followed by

\begin{tabular}{lrl}
\hline $\begin{array}{l}\text { Table } 2 \text { ICD chapter headings of primary diagnosis: } \\
\text { January 2008-June 2013 (N=2106) }\end{array}$ & \multicolumn{1}{l}{} \\
\hline ICD chapter heading & 660 & \multicolumn{1}{l}{$\%$} \\
\hline Mental and behavioural disorders & 473 & 22.4 \\
\hline Injury, poisoning and other externalities & 233 & 11.1 \\
\hline Pregnancy, childbirth and puerperium & 75 & 3.6 \\
\hline Disease of skin and subcutaneous tissue & 157 & 7.4 \\
\hline Symptoms, unclassified & 86 & 4.1 \\
\hline Diseases of the respiratory system & 62 & 2.9 \\
\hline Factors influencing health status & 64 & 3.0 \\
\hline Diseases of the digestive system & 79 & 3.7 \\
\hline Diseases of the nervous system & 50 & 2.4 \\
\hline Diseases of musculoskeletal system and & & \\
connective tissue & 36 & 1.7 \\
\hline Diseases of the circulatory system & 38 & 1.8 \\
\hline Diseases of the genitourinary system & 35 & 1.7 \\
\hline Infectious and parasitic disease & 23 & 1.1 \\
\hline Endocrine, nutritional and metabolic disease & 29 & 1.4 \\
\hline Neoplasms & 6 & 0.3 \\
\hline Diseases of the eye, adnexa, ear and & & \\
\hline mastoid & & \\
\hline ICD, In & & \\
\hline
\end{tabular}

ICD, International Classification of Diseases.

drug-related diagnoses (39\%) and mental and behavioural disorders (34\%) (table 3). The majority (71\%) of all separations had three or more diagnostic codes.

Over two-thirds $(68 \%)$ of separations involved admission through the ED, and under half of admissions (40\%) resulted in multiday separations of between 2 and 506 days (table 4). Over three-quarters of separations (84\%) required a medical intervention. Most patients $(83 \%)$ were discharged to private residences; $33 \%$ were referred to a GP, while $33 \%$ had no referral or support services arranged at discharge. The largest percentage of non-residential discharge was attributed to patients leaving against medical advice (41\%), followed by transfers to extended stay and rehabilitation centres $(35 \%)$.

Table 3 Clinical categories of interest at hospital separations based on diagnoses: January 2008-June 2013 $(\mathrm{N}=2106)$

\begin{tabular}{|c|c|c|}
\hline Clinical categories & $\begin{array}{l}\text { Primary diagnosis, } \\
\text { n (\%) }\end{array}$ & $\begin{array}{l}\text { All diagnoses, } \\
\mathrm{n}(\%)^{\star}\end{array}$ \\
\hline Drug related & $312(14.8)$ & 828 (39.3) \\
\hline Injuries & $233(11.1)$ & $349(16.6)$ \\
\hline $\begin{array}{l}\text { Bacterial and skin } \\
\text { infections }\end{array}$ & $89(4.2)$ & 166 (7.9) \\
\hline Alcohol & $47(2.2)$ & $180(8.5)$ \\
\hline Mental health & $496(23.5)$ & $713(33.9)$ \\
\hline Social circumstances & $43(2.0)$ & $1323(62.9)$ \\
\hline
\end{tabular}

${ }^{\star}$ Each separation can have multiple categories. 
Table 4 People who inject drugs (PWID) hospital separation rates stratified by age compared with the Greater Melbourne population: 2008-2012

\begin{tabular}{lllll}
\hline $\begin{array}{l}\text { Age } \\
\text { group (years) }\end{array}$ & $\mathbf{n ~ ( \% )}$ & $\begin{array}{l}\text { MIX } \\
\text { (per 100 person-years) }\end{array}$ & $\begin{array}{l}\text { Greater Melbourne } \\
\text { (per 100 person-years) }\end{array}$ & $\begin{array}{l}\text { Age-standardised } \\
\text { rate ratio }\end{array}$ \\
\hline $15-24$ & $505(25.1)$ & $63.5(95 \%$ Cl 58.1 to 69.3) & 20.9 & $3.0(2.8-3.3)$ \\
\hline $25-29$ & $809(37.3)$ & $53.0(95 \%$ Cl 49.4 to 56.8) & 31.9 & $1.7(1.5-1.8)$ \\
$30-49$ & $578(37.6)$ & $54.0(95 \%$ Cl 49.7 to 58.6) & 36.5 & $1.5(1.4-1.6)$ \\
\hline
\end{tabular}

MIX, Melbourne Injecting Drug User Cohort Study.

Trends in hospital separations: January 2008-June 2013 ( $\mathrm{N}=2106)$

There was a $12 \%$ increase in biannual separations per person over the study period ( $b=0.12 ; 95 \%$ CI 0.09 to $0.15, \mathrm{p}<0.001$ ) (figure 1). The largest number of annual separation sets was 443, occurring in 2012.

\section{Comparison of hospital separation rates for PWID and the general population}

The overall separation rate for the cohort between January 2008 and June 2013 was 50.6 per 100 PY (95\% CI 48.4 to 52.8). When the 214 separations in 2013 were excluded, age-stratified separation rates were higher than in the general population across all age groups, with the largest ratio in the youngest age group (table 4). There were 881 annual separation sets, with a median of two (IQR 1-2) and a maximum of 30 separations in a set.

\section{Prevalence and correlates of frequent hospital separations}

There were 1460 frequent separations among 1892 separations between 2008 and 2012. Over a quarter (29\%) of the cohort had at least one frequent separation episode in a calendar year. Separations classified as frequent comprised $77 \%$ of the total separations. The most common principal diagnosis in frequent separations was 'mental health related' (28\%), while a principal drug-related diagnosis was present in $15 \%$ of frequent separations.

When considering clinical categories of interest across all diagnoses at separations, only the mental health-related category was correlated with an increased likelihood of frequent separations (table 5). Being discharged to locations other than private residences, having a medical rather than surgical intervention, having an overnight or multiday separation, and having a separation in spring or winter were also more common among frequent separations. Conversely, being men and being diagnosed with the clinical category of bacterial and skin infections was associated with a lower likelihood of frequent separations. In the sensitivity analysis, replacing all diagnoses with principal diagnoses did not affect the clinical categories of interest that were significantly associated with frequent use.

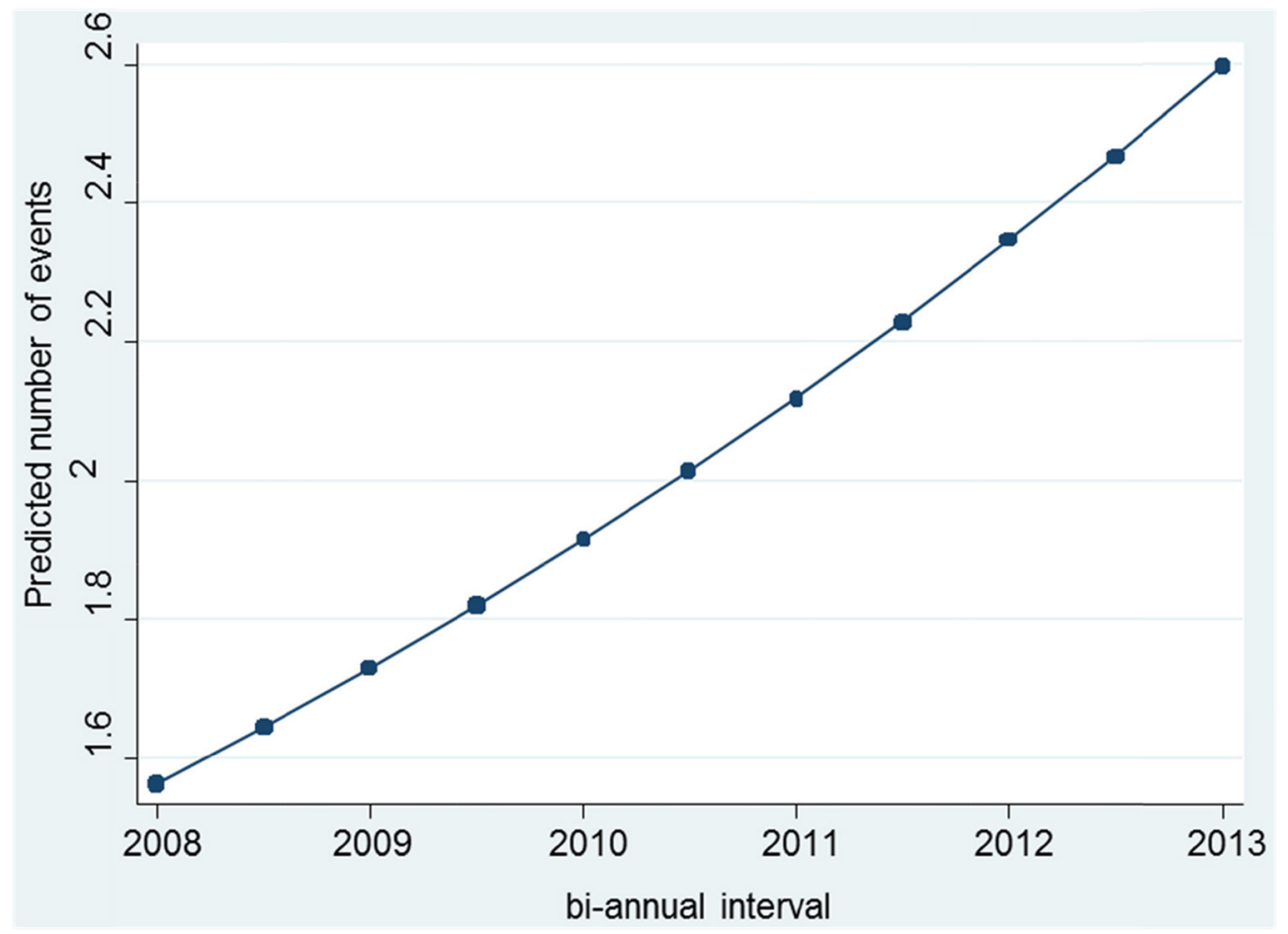

Figure 1 Trend in hospital separations: January 2008-June 2013 (N=2106). Test for trend, $\mathrm{p}<0.001$. 
Open Access

Table 5 Adjusted risk factors associated with frequent hospital admissions (all diagnoses): 2008-2012 ( $N=1892$ )

\begin{tabular}{|c|c|c|c|c|c|}
\hline Characteristic & n (\%) & $\begin{array}{l}\text { Frequent use, } \\
\mathrm{n}(\%)\end{array}$ & $\begin{array}{l}\text { Non-frequent use, } \\
\mathrm{n}(\%)\end{array}$ & OR $(95 \% \mathrm{Cl})$ & AOR $(95 \% \mathrm{Cl})$ \\
\hline \multicolumn{6}{|l|}{ Age (years) } \\
\hline $15-24$ & $505(25.1)$ & $402(27.5)$ & $103(23.8)$ & 1 & 1 \\
\hline $25-29$ & 809 (37.3) & $611(41.8)$ & $198(45.8)$ & $0.79(0.60 \text { to } 1.03)^{\star}$ & 0.85 (0.64 to 1.14$)$ \\
\hline $30-49$ & $578(37.6)$ & $447(30.6)$ & $131(30.3)$ & $0.87(0.65$ to 1.17$)$ & 1.01 (0.74 to 1.38$)$ \\
\hline Male & $943(49.8)$ & 701 (48.0) & $242(56.0)$ & $0.72(0.58$ to 0.90$) \dagger$ & 0.63 (0.50 to 0.80$) \dagger$ \\
\hline \multicolumn{6}{|l|}{ Single } \\
\hline No/unknown & 264 (12.5) & $197(11.8)$ & $67(15.5)$ & 1 & 1 \\
\hline Yes & $1842(87.5)$ & 1477 (88.2) & $365(84.5)$ & $1.40(1.03$ to 1.90$) \dagger$ & $1.36(0.97 \text { to } 1.90)^{\star}$ \\
\hline \multicolumn{6}{|l|}{ Season } \\
\hline Spring & $512(31.5)$ & $512(28.2)$ & $100(23.1)$ & 1.53 (1.14 to 2.07$) \dagger$ & $1.60(1.16$ to 2.20$) \dagger$ \\
\hline Summer & $471(25.8)$ & $351(24.0)$ & $120(27.8)$ & 1.09 (0.81 to 1.46$)$ & 1.10 (0.81 to 1.50$)$ \\
\hline Autumn & $453(18.6)$ & $330(22.6)$ & $123(28.5)$ & 1 & 1 \\
\hline Winter & $456(24.0)$ & $367(25.1)$ & $89(20.6)$ & 1.54 (1.13 to 2.10$) \dagger$ & 1.71 (1.23 to 2.38$) \dagger$ \\
\hline \multicolumn{6}{|l|}{ Admission type } \\
\hline Planned & 441 (23.3) & 334 (22.9) & $107(24.8)$ & 1 & - \\
\hline Emergency & $1312(69.3)$ & 1025 (70.2) & $287(66.4)$ & 1.14 (0.89 to 1.47$)$ & \\
\hline Maternity & $139(7.3)$ & $101(6.9)$ & $38(8.8)$ & 0.85 (0.55 to 1.31$)$ & \\
\hline \multicolumn{6}{|l|}{ Type of stay } \\
\hline Multiday & $757(40.0)$ & $610(41.8)$ & $147(34.0)$ & $1.90(1.48$ to 2.44$) \dagger$ & 1.54 (1.15 to 2.05$) \dagger$ \\
\hline Same day & $614(32.4)$ & $421(28.8)$ & $193(44.7)$ & 1 & 1 \\
\hline Overnight & $521(27.5)$ & $429(29.4)$ & $92(21.3)$ & 2.14 (1.61 to 2.83$)$ & 1.73 (1.28 to 2.33$) \dagger$ \\
\hline \multicolumn{6}{|l|}{$\begin{array}{l}\text { Type of } \\
\text { intervention }\end{array}$} \\
\hline Surgical & $293(15.5)$ & $181(12.4)$ & $112(25.9)$ & 1 & 1 \\
\hline Medical & $1599(84.5)$ & 1279 (87.6) & $320(74.1)$ & 2.47 (1.89 to 3.22$) \dagger$ & 1.95 (1.45 to 2.63$) \dagger$ \\
\hline \multicolumn{6}{|l|}{$\begin{array}{l}\text { Discharge } \\
\text { status }\end{array}$} \\
\hline Residence & $1587(83.9)$ & $1186(81.2)$ & $401(92.8)$ & 1 & 1 \\
\hline Other & $305(16.1)$ & $274(18.8)$ & $31(7.2)$ & $2.99(2.03$ to 4.41$) \dagger$ & 3.01 (2.00 to 4.52$) \dagger$ \\
\hline \multicolumn{6}{|l|}{$\begin{array}{l}\text { Clinical } \\
\text { categories }\end{array}$} \\
\hline Drug related & $744(39.3)$ & $601(41.2)$ & $143(33.1)$ & $1.41(1.13$ to 1.77$) \dagger$ & 0.90 (0.70 to 1.17$)$ \\
\hline Injuries & 319 (16.9) & $220(15.1)$ & $99(22.9)$ & $0.60(0.46$ to 0.78$) \dagger$ & 0.82 (0.61 to 1.10$)$ \\
\hline $\begin{array}{l}\text { Bacterial and } \\
\text { skin infections }\end{array}$ & $144(7.6)$ & $100(6.8)$ & 44 (10.2) & $0.65(0.45 \text { to } 0.94)^{*}$ & 0.65 (0.43 to 0.98$) \dagger$ \\
\hline Alcohol & $162(8.6)$ & $130(8.9)$ & $32(7.4)$ & 1.22 (0.82 to 1.83$)$ & 1.30 (0.84 to 2.00$)$ \\
\hline Mental health & 637 (33.7) & $570(39.0)$ & $67(15.5)$ & 3.49 (2.63 to 4.62$) \dagger$ & 2.52 (1.85 to 3.44$) \dagger$ \\
\hline $\begin{array}{l}\text { Social } \\
\text { circumstances }\end{array}$ & 1159 (10.6) & $906(62.0)$ & $253(58.6)$ & 1.16 (0.93 to 1.44$)$ & 1.23 (0.96 to 1.58$)$ \\
\hline
\end{tabular}

${ }^{*} \mathrm{p}<0.1$.

$\dagger \mathrm{p}<0.05$.

AOR, adjusted OR.

\section{DISCUSSION/CONCLUSION}

Between January 2008 and June 2013, more than half of the cohort members had at least one hospital separation, the majority through EDs. We found separation rates among PWID were up to three times higher than in the age-matched general population and frequent separations, defined as two or more separations within a 12-month period, related to the types of separations described 
in the general population, such as mental health-related conditions and non-residential discharge. ${ }^{28} 29$ The increased risk of hospital separations potentially relates to a tendency for PWID to only seek care once their medical complications have become severe ${ }^{30} 31$ and reflects in part the impoverished social circumstances (eg, homelessness) many PWID experience. ${ }^{32}$ The $1.4 \%$ annual increase in Australian hospital separations between 20082009 and $2012-2013^{33}$ was lower than the $12 \%$ biannual increase observed in the cohort. This finding, coupled with higher rates of hospital separations than in the general population, is of concern given the MIX cohort is relatively young, has access to universal healthcare and harm reduction, and has a high uptake of GP services. ${ }^{34}$ It is possible that the large increase in separations overtime was driven by declining health in the cohort due to ageing and lengthening injecting careers. Some of this increase may also be attributed to the implementation of the National Emergency Access Target (NEAT) from 2012, with a 4-hour target for ED stays, which may have resulted in an increase in this route of admission. ${ }^{19}$ An exploratory analysis indicated that there was a statistically significant increase across all admission types during the implementation of the NEAT (data not shown), but we were unable to examine this in detail because most hospital admissions were through the $\mathrm{ED}$, resulting in a lack of power for more detailed analyses.

Interventions that have sought to divert frequent users of hospitals to primary care services in the general population have achieved only partial success, possibly because there is a small group of frequent users with a genuine need for inpatient care. ${ }^{35}$ Targeting PWID who are frequent attenders with multiple health conditions for case management to facilitate access to health, harm reduction and social services may have the greatest impact on reducing frequent separations. In this regard, we found frequent separations associated with mental health conditions (which can be caused or exacerbated by drug use ${ }^{4}$ ) but not drug-related diagnoses. Mental health conditions among PWID may be a marker of more entrenched drug use, ${ }^{36}$ as heavy substance use is correlated with frequent hospital separations in the general population. ${ }^{37}$ Previous work shows that mental health and substance use comorbidities increase the rate of ED presentation ${ }^{29}$; however, in our study, while mental health conditions were associated with frequent hospital separations, drug-related diagnoses were not. It is possible that in some cases drug use was not identified, or that participants were not actively consuming or injecting at the time ${ }^{25}$ and were not screened for previous substance use. Failure to identify drug use during a hospital admission represents a missed opportunity to provide harm reduction and pathways to treatment ${ }^{4}$ and may increase the risk of further complications from drug-drug interactions. ${ }^{38}$ The high correlation between substance use and mental health disorders ${ }^{36}$ suggests that referrals to integrated mental health and drug treatment services will be more effective than individual programmes in reducing readmission rates. ${ }^{29}$
We also found discharge to locations other than the patients' residence and longer stays were associated with frequent separations. Of the former, the most common discharge codes were leaving against medical advice, followed by transfers to extended or rehabilitative care and mental healthcare. Substance use has been associated with incomplete episodes of care ${ }^{39}$ which often leads to representations at EDs. ${ }^{28}$ Similarly, a longer length of stay has been associated with readmissions in the general population ${ }^{23}$ potentially due to the complexity of the condition and social issues such as lack of care and unstable housing, which can prevent immediate discharge. ${ }^{40}$ These factors reiterate the impact on health and resources of the lifestyle issues PWID face. Multidisciplinary case management and referrals targeting both health and social conditions for frequent users implemented through hospital services may assist vulnerable patients to access appropriate health and community services at discharge. ${ }^{41}$

Our results should be interpreted with caution for several reasons. As described, deterministic linkage may have led to conservative estimates of hospital separations, and data collected across Victorian hospitals precludes any interstate hospital use. There is likely to be some underascertainment from missing information and typographical errors in hospital registries. ${ }^{42}$ There may be inconsistencies in data collected from multiple hospitals; however, the linked file was supplemented by a data dictionary which we used to interpret variables. Given the sensitive nature of the data and the cohort, deterministic linkage ensured high specificity, so only established separations that precisely characterise hospitalisation in the cohort were included. However, future linkage work should consider a combination of deterministic and probabilistic linkage, to balance specificity and sensitivity ${ }^{43}$ to overcome both errors at data collection and reliance on identifiers such as names in populations where many aliases may be present. ${ }^{44}$ The study period overlapped with the implementation of the NEAT, which was progressively rolled out from 2012 and aimed to reduce ED overcrowding. ${ }^{20}$ The NEAT may have increased hospital admission rates through EDs, but as indicated we were unable to determine whether this was the case. The GEE models applied in the regression analyses do not account for the order of events; the risk of each separation is independent and not affected by previous separations. Including all diagnoses overcomes reliance on clinical coding prioritisation, which may result in loss of relevant diagnoses,such as drug and mental health conditions because they were not the principal diagnosis. The cohort was recruited using multiple sampling methods, which may affect the generalisability of these results, but is similar to other Australian cohorts of PWID across the majority of demographics other than age. ${ }^{45} 46$

Our findings show a very high rate of separations among PWID that may at least in part be driven by their socioeconomic circumstances and related factors, such as unstable housing and mental health issues. Overtime 
the number of separations increased, probably due to increasing age, period of injecting and incidence of chronic diseases, but further research is needed to determine whether this pattern also reflects changes in ED practice. Within the PWID cohort, mental health conditions increased the likelihood of multiple hospital admissions. Strategies to address frequent admissions among PWID require targeted interventions that take mental health and social conditions into consideration. Hospitals are likely to remain the appropriate point of care for PWID with complex needs, given the availability of specialised services (such as psychiatry) at a low cost to patients. However, referrals to integrated drug and mental health services may reduce use of tertiary care.

Acknowledgements The authors thank study participants, interviewers and organisations involved in the recruitment of the MIX cohort. We thank Simon Brown, Katy Greenland, Ying Chen, Likhesh Mahajan and Pradeep Wijayaratne from the DoH and Human Services for extracting the data. We also thank Dr Gim Tan and Tracy Burgess of The Alfred Hospital, who were consulted regarding clinical coding practices. Some of the statistical methods were based on a previous paper that was developed under the guidance of Dr Tim Spelman, whom we also acknowledge.

Contributors DN led the design, analyses, interpretation and writing of the manuscript. PD contributed to the conception of the work, the acquisition of the data as well as the interpretation and revisions. MS contributed to the conception of the work, the acquisition of the data as well as the interpretation and revisions. $\mathrm{MH}$ contributed to the design of the analyses, interpretation of the results and revisions. All authors read and approved the final manuscript, and agreed to be accountable for all aspects of the work.

Funding The MIX study is funded by the Colonial Foundation Trust and the National Health and Medical Research Council (NHMRC Grant no. 545891). DN receives support from the NHMRC through a postgraduate scholarship awarded through the Burnet Institute Centre for Research Excellence into Injecting Drug Use (CREIDU— APP1001144). MS is an NHMRC Career Development Fellow and receives support through CREIDU.

Competing interests PD has received a untied educational grant from Reckitt Benckinser used for work unrelated to this paper, and MS and MH have received an investigator-driven grant from Gilead Sciences for work unrelated to this manuscript.

Ethics approval Victorian Department of Health and Monash University Human Research Ethics Committees.

Provenance and peer review Not commissioned; externally peer reviewed.

Data sharing statement All data in the study are included in this publication. The data is not publicly accessible due to the confidential nature of the medical records as well as its potentially identifiable nature.

Open Access This is an Open Access article distributed in accordance with the Creative Commons Attribution Non Commercial (CC BY-NC 4.0) license, which permits others to distribute, remix, adapt, build upon this work non-commercially, and license their derivative works on different terms, provided the original work is properly cited and the use is non-commercial. See: http://creativecommons.org/ licenses/by-nc/4.0/

(c) Article author(s) (or their employer(s) unless otherwise stated in the text of the article) 2017. All rights reserved. No commercial use is permitted unless otherwise expressly granted.

\section{REFERENCES}

1. Dwyer R, Topp L, Maher L, et al. Prevalences and correlates of non-viral injecting-related injuries and diseases in a convenience sample of Australian injecting drug users. Drug Alcohol Depend 2009;100:9-16.

2. Ivan $\mathrm{M}$, van Beek I, Wand $\mathrm{H}$, et al. Surveillance of injecting-related injury and diseases in people who inject drugs attending a targeted primary health care facility in Sydney's Kings Cross. Aust N Z J Public Health 2015;39:182-7.
3. Roxburgh A, Degenhardt L. Characteristics of drug-related hospital separations in Australia. Drug Alcohol Depend 2008;92:149-55.

4. Haber PS, Demirkol A, Lange K, et al. Management of injecting drug users admitted to hospital. Lancet 2009;374:1284-93.

5. Fairbairn N, Milloy MJ, Zhang R, et al. Emergency department utilization among a cohort of HIV-positive injecting drug users in a Canadian setting. J Emerg Med 2012;43:236-43.

6. Islam MM, Topp L, Iversen J, et al. Healthcare utilisation and disclosure of injecting drug use among clients of Australia's needle and syringe programs. Aust N Z J Public Health 2013;37:148-54.

7. Jonas H, Dietze P, Rumbold G, et al. Associations between alcohol related hospital admissions and alcohol consumption in Victoria: influence of socio-demographic factors. Aust N Z J Public Health 1999;23:272-9.

8. Department of Health and Human Services. Victorian emergency Minimum Dataset (VEMD): Accessible and Restricted Data Fields. Canberra: DHHS, 2012.

9. Department of Health and Human Services. Victorian Admitted Episodes Dataset (VAED): Accessible and Restricted Data Fields. Canberra: DHHS, 2012.

10. Stein MD, O'Sullivan PS, Ellis P, et al. Utilization of medical services by drug abusers in detoxification. $J$ Subst Abuse 1993;5:187-93.

11. O'Toole J, Hambly R, Cox AM, et al. Methadone-maintained patients in primary care have higher rates of chronic disease and multimorbidity, and use health services more intensively than matched controls. Eur J Gen Pract 2014;20:275-80.

12. Marks M, Pollock E, Armstrong M, et al. Needles and the damage done: reasons for admission and financial costs associated with injecting drug use in a Central London Teaching Hospital. $J$ Infect 2013;66:95-102.

13. Burns L, Conroy E, Mattick RP. Main reasons for hospital admissions by women with a history of methadone maintenance. Drug Alcohol Rev 2010;29:669-75.

14. Whittaker E, Swift W, Roxburgh A, et al. Multiply disadvantaged: health and service utilisation factors faced by homeless injecting drug consumers in Australia. Drug Alcohol Rev 2015;34:379-87.

15. Kushel MB, Vittinghoff E, Haas JS. Factors associated with the health care utilization of homeless persons. JAMA 2001;285:200-6.

16. Kelly E, McKetine R, McLaren J. Health service utilisation among regular methamphetamine users. NDARC Technical Report. Sydney: National Drug and Alcohol Research Centre, 2005.

17. Palepu A, Tyndall MW, Leon $\mathrm{H}$, et al. Hospital utilization and costs in a cohort of injection drug users. CMAJ 2001;165:415-20.

18. Horyniak D, Higgs P, Jenkinson R, et al. Establishing the Melbourne Injecting Drug user Cohort Study (MIX): rationale, methods, and baseline and twelve-month follow-up results. Harm Reduct $J$ 2013;10:11

19. Australian Institute of Health and Welfare. Australian hospital statistics: national emergency access and elective surgery targets. Canberra: AlHW: Health Services Series No. 48 Cat. no. HSE 131, 2012.

20. Australian Bureau of Statistics. 1270.0.55.001. Australian Statistical Geography Standard (ASGS):Volume 1 - Main Structure and Greater Capital City Statistical Areas, July 2011. Canberra: Australian Bureau of Statistics, 2011.

21. Cameron M, Robinson K. The effects on clinical coding of the critical pathway recording methodology. Him J 2004;32:74-83.

22. Robinson K, Shepheard J. Predicting the influence of the electronic health record on clinical coding practice in hospitals. Him J 2004;32:102-8.

23. Halfon $P$, Eggli $Y$, van Melle $G$, et al. Measuring potentially avoidable hospital readmissions. J Clin Epidemiol 2002;55:573-87.

24. Fuda KK, Immekus R. Frequent users of Massachusetts emergency departments: a statewide analysis. Ann Emerg Med 2006;48:16. e1-16.e8.

25. Nambiar D, Agius PA, Stoové M, et al. Cessation of injecting drug use: The effects of health service utilisation, drug use and demographic factors. Drug Alcohol Depend 2015;154:208-13.

26. Islam MM, Topp L, Conigrave KM, et al. Are primary health care centres that target injecting drug users attracting and serving the clients they are designed for? A case study from Sydney, Australia. Int J Drug Policy 2013;24:326-32.

27. Darke S, Ross J, Mills KL, et al. Patterns of sustained heroin abstinence amongst long-term, dependent heroin users: 36 months findings from the Australian Treatment Outcome Study (ATOS). Addict Behav 2007;32:1897-906.

28. Moore G, Gerdtz M, Manias E, et al. Socio-demographic and clinical characteristics of re-presentation to an Australian inner-city emergency department: implications for service delivery. BMC Public Health 2007;7:320. 
29. Curran GM, Sullivan G, Williams K, et al. Emergency department use of persons with comorbid psychiatric and substance abuse disorders. Ann Emerg Med 2003;41:659-67.

30. Drumm RD, McBride DC, Metsch L, et al. "The rock always comes first": drug users' accounts about using formal health care. $J$ Psychoactive Drugs 2003;35:461-9.

31. Friedmann PD, Hendrickson JC, Gerstein DR, et al. Do mechanisms that link addiction treatment patients to primary care influence subsequent utilization of emergency and hospital care? Med Care 2006;44:8-15.

32. Palepu A, Strathdee SA, Hogg RS, et al. The social determinants of emergency department and hospital use by injection drug users in Canada. J Urban Health 1999;76:409-18.

33. Australian Institute of Health and Welfare. Australian hospital statistics 2012-13. Canberra: AlHW, 2014.

34. Nambiar D, Stoové M, Dietze P. A cross-sectional study describing factors associated with utilisation of GP services by a cohort of people who inject drugs. BMC Health Serv Res 2014;14:308.

35. Dent AW, Phillips GA, Chenhall AJ, et al. The heaviest repeat users of an inner city emergency department are not general practice patients. Emergency Medicine Australasia 2003;15:322-9.

36. Teesson M, Marel C, Darke S, et al. Long-term mortality, remission, criminality and psychiatric comorbidity of heroin dependence: 11-year findings from the Australian Treatment Outcome Study. Addiction 2015;110:986-93.

37. French MT, Fang $\mathrm{H}$, Balsa Al. Longitudinal analysis of changes in illicit drug use and health services utilization. Health Serv Res 2011;46:877-99.
38. Palleria C, Di Paolo A, Giofrè C, et al. Pharmacokinetic drug-drug interaction and their implication in clinical management. J Res Med Sci 2013;18:601-10.

39. Alfandre DJ. "I'm going home": discharges against medical advice. Mayo Clin Proc 2009;84:255-60.

40. Coast J, Peters TJ, Inglis A. Factors associated with inappropriate emergency hospital admission in the UK. Int J Qual Health Care 1996;8:31-9.

41. Phillips GA, Brophy DS, Weiland TJ, et al. The effect of multidisciplinary case management on selected outcomes for frequent attenders at an emergency department. Med J Aust 2006;184:602-6.

42. Setoguchi S, Zhu Y, Jalbert JJ, et al. Validity of deterministic record linkage using multiple indirect personal identifiers: linking a large registry to claims data. Circ Cardiovasc Qual Outcomes 2014;7:475-80.

43. Harron K, Wade A, Gilbert R, et al. Evaluating bias due to data linkage error in electronic healthcare records. BMC Med Res Methodol 2014;14:36.

44. Snow KJ, Young JT, Preen DB, et al. Incidence and correlates of hepatitis $\mathrm{C}$ virus infection in a large cohort of prisoners who have injected drugs. BMC Public Health 2014;14:830.

45. Islam MM, Topp L, Conigrave KM, et al. Opioid substitution therapy clients' preferences for targeted versus general primary health-care outlets. Drug Alcohol Rev 2013;32:211-4.

46. Darke S, Slade T, Ross J, et al. Patterns and correlates of alcohol use amongst heroin users: 11-year follow-up of the Australian treatment Outcome Study cohort. Addict Behav 2015;50:78-83. 